\title{
A Kinetic Consideration on the Oxidation of Methylbenzenes by Cerium Ion Mediators
}

\author{
Masayuki MorITA*, Singo KITAMURA, Masashi ISHIKAWA \\ and Yoshiharu MATSUDA
}

Received June 2, 1994 ; Accepted August 10, 1994

\begin{abstract}
The indirect electrooxidation of substituted methylbenzenes to arylaldehydes by $\mathrm{Ce}$ (IV) mediators has been studied. The yield and selectivity of the aldehyde varied with the combination between the substrate compound and the mediator. The reaction mode was characterized by the relationship between the oxidation potential of the substrate $\left(E_{s, o x}\right)$ and the apparent redox potential of the mediator $\left(E_{m, r e d}\right)$. The second-order rate constant for the oxidation of the methylbenzenes with the oxidized mediators depended on the potential difference, $\Delta E=E_{s, o x}$ $E_{m, r e d}$. Marcus's electron-transfer theory was apparently applied for endothermic systems. High yields of aldehydes were obtained when the systems had moderate values of $\Delta E$.
\end{abstract}

\section{INTRODUCTION}

Cerium(III)/cerium(IV) redox couples are efficient mediators for indirect electrooxidation of side chains of aromatic compounds yielding such carbonyl compounds as arylaldehydes, ketones and acids ${ }^{1-6)}$. Those processes employ different cerium salts in various acidic media. The synthetic conditions greatly affect the yields and selectivity of the products, being similar to the cases of conventional organic syntheses. Among them, choice of the acid is of special importance because it is concerned not only with the solution $\mathrm{pH}$ affecting solubility and stability of substances but also with the redox potential of the mediator?). However, few have been known about the basic relation among the substrate/ mediator combination, the reaction rate and the product selectivity.

In the previous paper ${ }^{8}$, we dealt with the indirect electrooxidation of substituted alkylbenzenes with metal-ion mediators. The yields of the reaction products were qualitatively explained by the mutual

Department of Applied Chemistry and Chemical Engineering, Faculty of Engineering, Yamaguchi University (Tokiwadai, Ube 755, Japan) Key Words: Indirect Electrooxidation, Cerium Mediator, Arylaldehydes, Reaction Rate. relation between the oxidation potential of the substrate and the reduction potential of the oxidized mediator. In this work, we examined a series of substituted methylbenzene/cerium(III)/(IV) mediator combinations to yield the corresponding arylaldehydes. The relation between the product yields and the substrate/mediator combinations is discussed from the viewpoint of the reaction rate that should depend on the potential difference of the substrate/ mediator combination. That is, we would stress the significance of the electrochemical congeniality between the organic substrate and the redox mediator through the variation in the electron transfer rate.

\section{EXPERIMENTAL}

An "ex-cell method"9) was employed in this work to exclude any effects caused by direct electrochemical reactions of the substrates at the anode 8,10 ). Mediators were generated by anodic oxidation of reduced form cerium salts, cerium(III) sulfate $\left(\mathrm{Ce}_{2}\left(\mathrm{SO}_{4}\right)_{3}\right)$, cerium(III) perchlorate $\left(\mathrm{Ce}\left(\mathrm{ClO}_{4}\right)_{3}\right)$ and cerium(III) methanesulfonate $\left(\mathrm{Ce}\left(\mathrm{CH}_{3} \mathrm{SO}_{3}\right)_{3}\right)$, which were dissolved in the corresponding aqueous acids. The substrates were toluene, $p$-xylene, $p$ methyl-anisole and $p$-methylphenetole with extrapure grade, and used without further purification.

An H-shape glass cell equipped with a glass filter 
diaphragm was used for the oxidation of the mediator. The working and counter electrodes were Pt sheets. An SCE connected with the working electrode through a Luggin capillary was used as the reference electrode. The electrolysis was carried out under controlled potential conditions. After the aqueous solution $\left(100 \mathrm{~cm}^{3}\right)$ containing the oxidized mediator was transferred to a glass vessel in a thermostatted bath, the organic substrate dissolved in benzene $\left(0.1 \mathrm{~mol} \mathrm{dm}-3,10 \mathrm{~cm}^{3}\right)$ was added to the mediator solution. The organic/aqueous two-phase mixture was stirred at $25^{\circ} \mathrm{C}$. The reaction products were quantitatively analyzed for each given time by GC and HPLC. The recovery of the oxidized mediator was determined by redox titration.

To determine the practical redox potentials of the mediators, current-potential curves were measured in aqueous acidic solutions under steady-state conditions. The electrochemical reactivity of the substrate was evaluated by cyclic voltammetry in acetonitrile, dissolving the substrate and $\mathrm{NaBF}_{4}$ $\left(0.05 \mathrm{~mol} \mathrm{dm}^{-3}\right)$ as the supporting electrolyte ${ }^{8}$.

\section{RESULTS AND DISCUSSION}

Figure 1 shows cyclic voltammograms for direct electrochemical oxidation of substrates at a $\mathrm{Pt}$ anode in acetonitrile. The anodic current increases are based on the one-electron transfer reaction to form cation radicals 1,11 ). The on-set potential of the current increase, which is defined as a nominal oxidation potential $\left(E_{s, o x}\right)$, depended on the substituent group of the methylbenzenes. The $E_{s, o x}$ values determined here include additional overvoltages at the anode as well as the standard oxidation potential of the substrate. However, we can use those as a measure of the reactivity for the oxidation reaction because the overvoltage at the $\mathbf{P t}$ anode is assumed to be constant throughout a series of substituted methylbenzenes. The relation between $E_{s, o x}$ and Hammett's constant of the substituent group $(\sigma)$ showed a linear relation, which proves that $E_{s, o x}$ is valid as a measure of the HOMO energy of the substrate 8,12 ).

Polarization curves for the redox processes of the $\mathrm{Ce}(\mathrm{III}) /(\mathrm{IV})$ mediators were measured in acidic solutions containing equivalent amounts of $\mathrm{Ce}(\mathrm{III}) /$ $\mathrm{Ce}$ (IV) that were prepared by electrolysis of the $\mathrm{Ce}$ (III) solutions. A typical current-potential relation

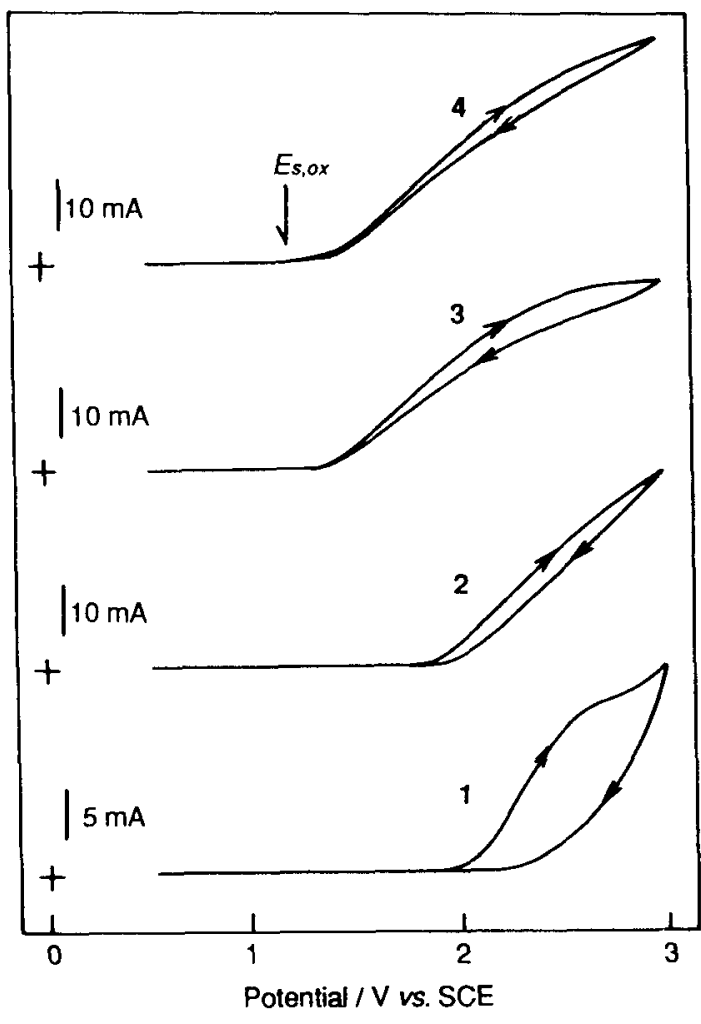

Fig. 1 Cyclic voltammograms for anodic oxidation of substituted methylbenzenes in $\mathrm{CH}_{3} \mathrm{CN}$ containing $0.05 \mathrm{~mol} \mathrm{dm}^{-3} \mathrm{NaBF}_{4}$. 1: Toluene, 2: $p$-Xylene, 3: $p$-Methylphenetole, 4: $p$-Methylanisole,

Substrate concentration: $0.1 \mathrm{~mol} \mathrm{dm}^{-3}$, Anode: $\mathrm{Pt}$, Scan rate: $0.05 \mathrm{~V} \mathrm{~s}^{-1}$.

is shown in Fig. 2. The potential where no net current was observed (rest potential) was defined as the nominal redox potential $\left(E_{m, r e d}\right)$ of the $\mathrm{Ce}(\mathrm{III}) / \mathrm{Ce}$ (IV) couple. We found, for example in Fig. 2, that $E_{m, r e d}$ in $\mathrm{H}_{2} \mathrm{SO}_{4}$ is $1.21 \mathrm{~V}$ vs. SCE. The $E_{m, r e d}$ values in different acid solutions are summarized in Table 1 , where $E_{s, o x}$ 's of the substrates are also listed. Changes in $E_{m, \text { red }}$ values with acids are attributable to the differences in the chemical structures of actual $\mathrm{Ce}$ (III)/(IV) species in the acidic solutions. For example, $\mathrm{Ce}(\mathrm{IV})$ in $\mathrm{HClO}_{4}$ is hydrolyzed to $\mathrm{Ce}(\mathrm{OH})^{3+}$ and $\mathrm{Ce}(\mathrm{OH})_{2}{ }^{2+}$ complex ions ${ }^{13)}$, while that in concentrated $\mathrm{H}_{2} \mathrm{SO}_{4}$ is considered to form $\mathrm{Ce}\left(\mathrm{SO}_{4}\right){ }_{3}{ }^{2-}$ complex ${ }^{14)}$. Thus, the order of the $E_{m, r e d}$ value, which is a measure of the oxidizing power of the mediator, was Ce(III)/(IV) 
in $\mathrm{H}_{2} \mathrm{SO}_{4}<$ in $\mathrm{CH}_{3} \mathrm{SO}_{3} \mathrm{H}<$ in $\mathrm{HClO}_{4}$.

The results of the oxidation of methylbenzenes to arylaldehydes by Ce(IV) are summarized in Table 2 . In most cases aldehydes were obtained as the main products though the conditions were not optimized. However, the yields of the aldehydes much depended

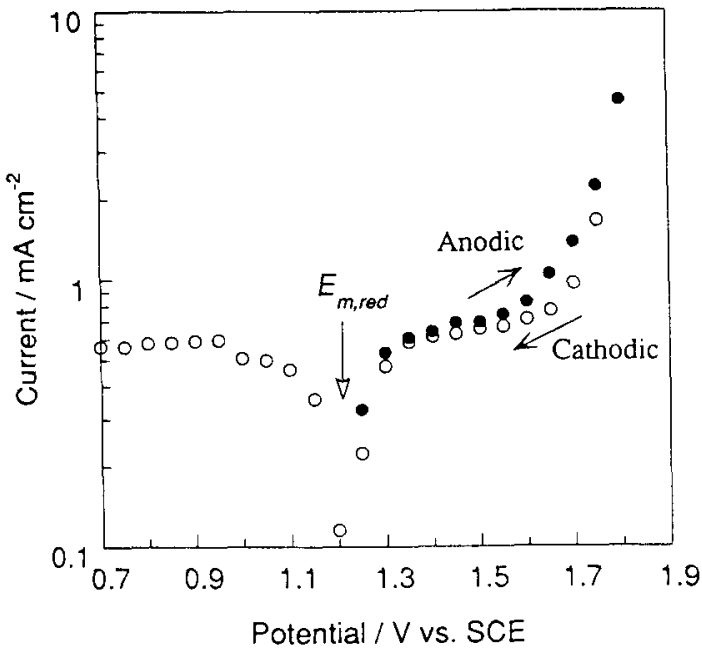

Fig. 2 Steady-state current-potential curves at $\mathrm{Pt}$ in $2.0 \mathrm{~mol} \mathrm{dm}^{-3} \mathrm{H}_{2} \mathrm{SO}_{4}$ containing $0.05 \mathrm{~mol} \mathrm{dm}^{-3}$ $\mathrm{Ce}_{2}\left(\mathrm{SO}_{4}\right)_{3}$. on the combination of the substrate and the acid dissolving $\mathrm{Ce}$ (IV) mediator (substrate/mediator combination). Especially, the combinations of high $E_{s, o x}$ and low $E_{m, r e d}$, or low $E_{s, o x}$ and high $E_{m, r e d}$, gave very low yields of the aldehydes. In the former cases, eg. oxidation of $p$-xylene by $\mathrm{Ce}$ (IV) in $\mathrm{H}_{2} \mathrm{SO}_{4}$, unreacted $\mathrm{Ce}(\mathrm{IV})$ was recovered with high efficiencies. Contrary to this, the recovery of $\mathrm{Ce}$ (IV) was practically zero for the latter combinations, eg. oxidation of $p$-methylanisole in $\mathrm{HClO}_{4}$.

The reaction rate of the aldehyde formation was determined from the variation in the concentration of the product aldehyde as a function of reaction time. The reaction obeyed second-order kinetics at its initial stage. In most cases the concentration change in $\mathrm{Ce}$ (IV) was equivalent to that of the formed aldehyde at the initial period of the reaction, but in some cases, as described below, the reaction lead to such byproducts as aromatic acids. The apparent rate constants for the oxidation of substituted methylbenzenes to aldehydes are summarized in Table 3. For the systems giving extremely low aldchyde yields, we did not determine the rate constants. Comparing the results shown in Tables 2 and 3 , the substrate/mediator combinations that lead

Table 1 Nominal oxidation potential of the substrate compound and redox potential of the mediator.

\begin{tabular}{lc}
\hline Substrate compound & $E_{s, o x} / \mathrm{V}$ vs. SCE \\
\hline$p$-Methylanisole & 1.22 \\
p-Methylphenetole & 1.25 \\
$p$-Xylene & 1.75 \\
Toluene & 1.88 \\
\hline
\end{tabular}

\begin{tabular}{lc}
\hline Mediator & $E_{m, r e d} / \mathrm{V} v s . \mathrm{SCE}$ \\
\hline $\mathrm{Ce}(\mathrm{III}) /(\mathrm{IV})$ & \\
in $\mathrm{H}_{2} \mathrm{SO}_{4}$ & 1.21 \\
in $\mathrm{CH}_{3} \mathrm{SO}_{3} \mathrm{H}$ & 1.44 \\
in $\mathrm{HClO}_{4}$ & 1.53 \\
\hline
\end{tabular}

Table 2 Indirect electrooxidation of substituted methylbenzenes by cerium (III)/(IV) mediators at $25^{\circ} \mathrm{C}$.

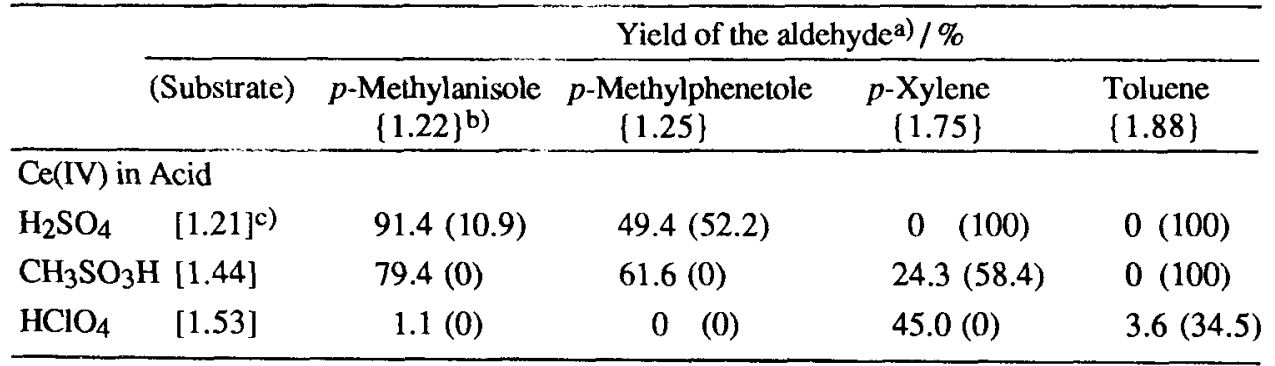

a) Based on $\mathrm{Ce}$ (IV), the values in parentheses are recovery of unreacted $\mathrm{Ce}(\mathrm{IV})$

b) ( ]: $E_{s, o x} / \mathrm{V}$ vs. SCE, c) [ ]: $E_{m, r e d} / \mathrm{V}$ vs. SCE. 
Table 3 Apparent rate constant for electrooxidation of aubetituted methylbenzenes by cerium (III)(IV) mediators $25^{\circ} \mathrm{C}$.

\begin{tabular}{lccccc}
\hline & \multicolumn{5}{c}{$k / \mathrm{mol}^{-1} \mathrm{dm}^{3} \mathrm{~s}^{-1}$} \\
\cline { 2 - 6 } & (Substrate) & $\begin{array}{c}p \text {-Methylanisole } \\
\left.\{1.22\}^{a}\right)\end{array}$ & $\begin{array}{c}p \text {-Methylphenetole } \\
\{1.25\}\end{array}$ & $\begin{array}{c}p \text {-Xylene } \\
\{1.75\}\end{array}$ & $\begin{array}{c}\text { Toluene } \\
{[1.88\}}\end{array}$ \\
\hline $\mathrm{Ce}(\mathrm{IV})$ in Acid & & & & - \\
$\left.\mathrm{H}_{2} \mathrm{SO}_{4}[1.21]^{\mathrm{b}}\right)$ & $9.93 \times 10^{-4}$ & $5.87 \times 10^{-4}$ & - & - \\
$\mathrm{CH}_{3} \mathrm{SO}_{3} \mathrm{H}[1.44]$ & $1.14 \times 10^{-2}$ & $9.25 \times 10^{-3}$ & $2.30 \times 10^{-4}$ & $1.33 \times 10^{-6}$ \\
$\mathrm{HClO}_{4} \quad[1.53]$ & - & - & $2.10 \times 10^{-3}$ & $3.33 \times 10^{-5}$ \\
\hline
\end{tabular}

a) \{ \}: $E_{s, a x} / V$ vs. SCE, b) [ ]: $E_{m, \text { red }} / V$ vs. SCE.

to high aldehyde yields tend to have moderate values of the rate constant. This tendency means that appropriate rates for the oxidation of methylbenzenes are preferable to the formation of the aldehydes. Lower rates of the oxidation reaction naturally yield less amounts of aldehydes. On the other hand, higher rates of the oxidation are liable to proceed further oxidation of product aldehydes, which leads to lower yields of aldehydes as well as lower recovery of $\mathrm{Ce}$ (IV) mediators. Strictly, however, the results in Table 2 do not coincide with the order in Table 3 (eg. a higher yield in $\mathrm{CH}_{3} \mathrm{SO}_{3} \mathrm{H} / p$-methylanisole than in $\mathrm{H}_{2} \mathrm{SO}_{4} / p$-methyl phenetole). As the present reaction consists of multistep processes, such individual character as sort of the ligand of the mediator might affect the selectivity of the reaction.

The apparent rate constants are plotted as a function of the potential difference $\Delta E\left(=E_{s, o x}\right.$ $\left.E_{m, r e d}\right)$ in Fig. 3. According to the Marcus theory 15), the rate constant for an outer-sphere electron-transfer reaction (Eq. (1)) is expressed by Eq. (2)

$$
\begin{aligned}
& \mathrm{A}+\mathrm{D}=\mathrm{A}^{-}+\mathrm{D}^{+} \\
& k=\mathrm{Z} \exp \left(-\Delta F^{*} / R T\right)
\end{aligned}
$$

where $Z$ is the collision number and $\Delta F^{*}$ is equivalent to the activation free energy in the system $\left(\Delta G^{\star}\right)$. In highly endothermic systems, $\Delta F^{*}$ is practically equal to the changes in the Gibbs energy of the system $\left.\left(\Delta G^{\circ}\right)^{16}\right)$. As $\Delta G^{\circ}$ is related to the potential difference of the redox couples $\left(E^{\circ} D-E_{A}^{\circ}\right)$ by Eq. (3), the rate constant is described as Eq. (4):

$$
\begin{aligned}
& \Delta G^{\circ}=F\left(E_{D}^{\circ}-E_{A}^{\circ}\right) \\
& \log k=-F\left(E_{D}^{\circ}-E_{A}^{\circ}\right) / 2.303 R T+\log Z
\end{aligned}
$$

where $F$ denotes the Faraday constant.

If the charge transfer reaction in the present redox mediator system proceeds via an outer-sphere

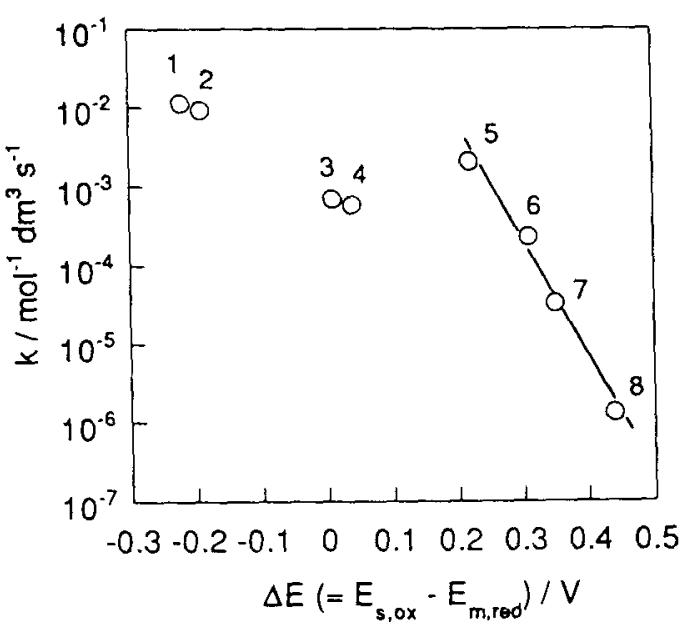

Fig. 3 Relation between the apparent rate constant and the potential difference for the $\mathrm{Ce}$ (IV) / methylbenzene systems.

1: $\mathrm{CH}_{3} \mathrm{SO}_{3} \mathrm{H} / p$-methylanisole, 2: $\mathrm{CH}_{3} \mathrm{SO}_{3} \mathrm{H} /$ $p$-methylphenetole, 3: $\mathrm{H}_{2} \mathrm{SO}_{4} / p$-methylanisole,

4: $\mathrm{H}_{2} \mathrm{SO}_{4} / p$-methylphenetole, $5: \mathrm{HClO}_{4} / p$-xylene

6: $\mathrm{CH}_{3} \mathrm{SO}_{3} \mathrm{H} / p$-xylene, $7: \mathrm{HClO}_{4} /$ toluene,

8: $\mathrm{CH}_{3} \mathrm{SO}_{3} \mathrm{H} /$ toluene.

process, the potential difference $E_{D}^{\circ}-E_{A}^{\circ}$ in Eq. (4) can be replaced by $\Delta E$. As $E_{s, o x}$ includes an overpotential for the electrode reaction, the $\Delta E$ value does not absolutely coincide with that of $E^{\circ} D-E_{A}^{\circ}$. However, relative values of $\Delta E$ should reflect those of $E^{\circ}{ }_{D}-E^{\circ}{ }_{A}$ in a series of mediator/substrate systems. A linear relation between $\log k$ and $\Delta E$ was observed for the systems of nos. $5-8$ in Fig. 3. The slope of the straight line $(-16.2)$ was essentially identical to the theoretical value $(-16.9)$ calculated from Eq. (4). This suggests that the first electron transfer from the substrate compound to the $\mathrm{Ce}^{4+}$ ion 
is rate-determining in the systems of nos. 5 - 8. As shown in Table 2, the recovery of unreacted $\mathrm{Ce}$ (IV) was generally high for this series, except for no. 5 . On the other hand, subsequent charge transfer or chemical processes should be slower than the first electron transfer during the oxidation processes in the systems of nos. 1 - 4. Higher yields of aldehydes were obtained for this series. However, higher electron transfer rates tend to cause some side reaction leading to lower aldehyde selectivities (nos. 1 and 2). The oxidation of the product aldehyde to the carboxylic acids as well as the oxidation of the solvent benzene would lead to such low selectivities (low aldehyde yields with low $\mathrm{Ce}$ (IV) recoveries).

The present results show that the mutual relation between the oxidation potential of the substrate and the redox potential of the mediator, which determines the initial reaction rate of the system, is primarily significant for designing the efficient indirect electrooxidation process. As the system, of course, consists of multi-electron transfer and some chemical processes, other reaction parameters such as $\mathrm{pH}$ in the aqueous solution and the solvent of the organic phase also affect the product yield and selectivity on the whole.

This work was financially supported by Grant-inAid for Scientific Research (nos. 05235234 and 06226258) from the Ministry of Education, Science and Culture, Japan.

\section{REFERENCES}

1) S. Torii, Electroorganic Synthesis (in Japanese), Kohdansha, Tokyo, Chap. 3 (1981).
2) L. Syper, Tetrahedron Lett., 1966, 4493.

3) T.L. Ho, Synthesis, 1973, 347.

4) R.P. Kreh, R.M. Spotnitz and J.T. Lundquist, Tetrahedron Lett., 28, 1067 (1987).

5) R.P. Kreh, R.M. Spotnitz and J.T. Lundquist, J. Org. Chem., 54, 1526 (1989).

6) R.M. Spotnitz, R.P. Kreh, J.T. Lundquist and P.J. Press, J. Appl. Electrochem., 20, 209 (1990).

7) H.B. Herman and J.R. Rairden, Encyclopedia of Electrochemistry of the Elements (Ed. A.J. $B$ ard), Vol. VI, Macel Dekker, New York, Chap. VI-2, p. 33 (1976).

8) M. Morita, T. Masatani and Y. Matsuda, Bull. Chem. Soc. Jpn., 66, 2747 (1993).

9) R. Clarke, A. Kuhn and E. Okoh, Chem. Br., 11, 59 (1975).

10) I. Nishiguchi and T. Hirashima, J. Org. Chem., 50, 539 (1985).

11) J.O. Howell, J.M. Concalves, C. Amatore, L. Klasinc, R.M. Wightman and J.K. Kochi, $J$. Am. Chem. Soc., 106, 3968 (1984).

12) C.J. Schlesener, C. Amatore and J.K. Kochi, J. Phys. Chem., 90, 3747 (1986).

13) M.S. Sherrill, C.B. King and R.C. Spooner, $J$. Am. Chem. Soc., 65, 170 (1943).

14) R.L. Moore and R.C. Anderson, J. Am. Chem. Soc., 67, 167 (1945).

15) R.A. Marcus, J. Chem. Phys., 24, 966 (1956): J. Chem. Phys., 26, 867 (1957).

16) S. Fukuzumi, K. Ishikawa, K. Hironaka and T. Tanaka, J. Chem. Soc., Parkin Trans. II, 1987, 751. 